\title{
ÚNG DỤNG WEBGIS TRONG GIÁM SÁT QUẢN LÝ, SỬ DỤNG TÀI NGUYÊN ĐÂT
}

\author{
NGUYẼ̃N PHI SƠN
}

Viện khoa hoc Đo đạc và Bản đồ

\section{Tóm tắt:}

Trong bài báo này giới thiệu kết quả xây dưng WebGIS do co quan quản lý đất đai cấp tỉnh quản lý, với 2 chức năng chinh là cung cấp các thông tin về đất đai và tiếp nhận các phản ánh của người dân, cộng đồng về các vi phạm trong quản lý, sử dụng đất, các thông tin về tai biến tụ nhiên trên đất. Các thông tin cung cấp của người dân và cộng đồng là nhũng nội dung theo đúng quy định của pháp luật trong thực hiện các quyền giám sát và hỗ trọ hoạt động giám sát của cơ quan quản lý. WebGIS có địa chỉ http://tainguyendat-quangninh.vn buớc đầu thưc nghiệm cho thành phố Uông Bí tỉnh Quảng Ninh. WebGIS được thiết kế công cu đồ họa để người dân và cộng đồng khoanh vẽ khu vục xảy ra vi phạm kèm theo các thông tin, hình ảnh, video. Đây là một công cu hỗ trọ hiệu quả trong quản lý nhà nước về đất đai.

Bài báo được xây dựng dựa trên số liệu và kết quả nghiên cứu của đề tài cấp nhà nuớc "Nghiên cưu ưng dụng công nghệ hiện đại trong xây dựng mô hình quản lý biến động tài nguyên, hoàn thiện công cu quản lý và nâng cao năng lực giám sát biến động sủ dụng đất" mã số BĐKH.10/16-20thuộc Chuơng trình Khoa hoc và công nghệ ứng phó với biến đổi khí hậu, quản lý tài nguyên và môi trường giai đoạn 2016-2020.

\section{Giới thiệu}

Sự tham gia của người dân trong việc giám sát các thay đổi của tài nguyên đất có nhiều ý nghĩa: Trước hết, nó cung cấp manh mối cho việc giám sát đất đai, khi người sử dụng đất, người dân có điều kiện và khả năng để tìm hiểu các hành vi bất hợp pháp mới bắt đầu xảy ra. Sự nhiệt tình của người dân khi cung cấp thông tin cho cơ quan quản lý sẽ tạo thuận lợi cho quá trình điều tra và xử phạt các hành vi bất hợp pháp. Người dân và cộng đồng tham gia giám sát đất đai như là "một bền" có liên quan tới "tài sản sở hữu toàn dân”. Lợi thế khi cộng đồng là ở khắp mọi nơi đều có những người hiểu biết về đất đai của địa phương mình và sẵn sàng cung cấp thông tin "bất thường" trong sử dụng đất, chi phí thấp và hiệu ứng tốt. Đặc biệt có thể nhận được thông tin ở những khu vực mà cơ quan công quyền không thể đến được. Có thể coi đó như là một lưới mạng giám sát liên tục. Thứ hai, sự tham gia của người dân trong việc giám sát có hiệu quả ngăn cản đối với các hành vi bất hợp pháp, mà có thể tạo thành phong trào đẩy lùi các hành vi bất hợp pháp, tăng cường hiệu ứng xã hội. Thư $b a$, sự tham gia của cộng đồng có ý nghĩa giáo dục, người sử dụng đất sẽ tăng cường sự hiểu biết về luật pháp, cho phép họ bảo vệ quyền lợi hợp pháp của mình. Thư $t u$, cộng đồng và người dân cũng có vai trò nhất định trong việc phát hiện các bất cập, sai trái trong công tác quản lý và thực thi pháp luật đất đai, làm giảm tập trung quyền lực. Tóm lại, sự tham gia của công chúng sẽ mang lại những thông tin thực thi pháp luật trực tiếp nhất, hiệu quả nhất và các đầu mối cho sự giám sát tài nguyên đất, không những trong quản lý, sử dụng mà còn trong bảo vệ và phát triển tài nguyên đất $[2,3]$.

Có nhiều cách thức để người dân lựa chọn tham gia trong việc giám sát đất đai, từ việc thiết lập hộp thư, đường dây nóng để báo cáo công khai, cũng như tiến hành giám sát các hành vi bất hợp pháp thông qua báo chí. Sử dụng Internet đã trở nên rất phổ biến là kênh thông tin cung cấp rất hiệu quả cho toàn xã hội. Các thông tin được 
cung cấp không chỉ dưới dạng chữ, hình ảnh, bảng biểu,... mà còn dưới dạng bản đồ trực tuyến nhờ sự hỗ trợ của công nghệ WebGIS [1].

WebGIS là một hệ thống thông tin địa lý sử dụng các công nghệ Web. Hệ thống sử dụng các công nghệ Web để giao tiếp giữa các thành phần khác nhau của hệ thống. WebGIS bắt nguồn từ sự kết hợp giữa công nghệ Web và hệ thống thông tin địa lý - GIS, là công nghệ được công nhận với thành phần chính là tập hợp các công cụ xử lý dữ liệu nhằm lữu trữ, phục hồi, quản lý và phân tích dữ liệu không gian. Internet đã trở nên thường thức đối với người dân và công nghệ GIS sẽ là một giải pháp hữu hiệu để chuyển tải các thông tin về pháp luật đất đai, về quy hoạch sử dụng đất, về hiện trạng sử dụng tài nguyên đất, về thoái hóa đất, ô nhiễm đất... đến từng người dân và cộng đồng. Việc lựa chọn giải pháp kỹ thuật và thiết kế công cụ tương tác cho người dùng cuối của WebGIS là điều cần thiết nhằm tạo ra các giao diện thân thiện, chức năng dễ sử dụng, để hầu hết người dân và cộng đồng có thể truy cập và trao đổi thông tin. Xuất phát từ thực tế đó việc xây dựng WebGIS để hỗ trợ hoạt động giám sát biến động tài nguyên đất là cần thiết. Đây là một sản phẩm của đề tài nghiên cứu khoa học, được triển khai thử nghiệm trên địa bàn thành phố Uông Bí, tỉnh Quảng Ninh. Mục tiêu của nghiên cứu là xây dựng được một công cụ tương tác với người dân và cộng đồng về tài nguyên đất thông qua bản đồ trực tuyến, cung cấp công cụ để người dân thông tin đến cơ quan quản lý về các vi phạm trong sử dụng đất, trong quản lý đất, thông tin về biến động của tài sản trên đất, các tai biến đất. Người dân và cộng đồng có thể vẽ trực tiếp trên Website, kèm theo các thông tin và hình ảnh, video cho cơ quan quản lý và được người quản trị tổng hợp, báo cáo cấp có thẩm quyền giải quyết.

\section{Phương pháp nghiên cứu}

\subsection{Lựa chọn công nghệ xây dụng hệ thống}

Hệ thống WebGIS được thiết kế trên nền tảng ASP.NET để phát triển ứng dụng Web, được xây dựng theo mô hình Client/Server. Phía Client sẽ điều khiển trực tiếp và tương tác với Webserver thông qua trình duyệt web, nhận được các thông tin hiển thị. Phía Server có nhiệm vụ lưu trữ, xử lý, tính toán và phân tích các dữ liệu không gian và thuộc tính sau đó gửi đến người dùng để người dùng xử lý tiếp, hoặc xem hay download dữ liệu. Trình duyệt HTML5 là ngôn ngữ markup web kết hợp với các ngôn ngữ JavaScript để điều khiển tương tác, gửi và nhận dữ liệu từ server [1].

CSDL được xây dựng bằng hệ quản trị SQL Server 2016. Phần mềm hệ quản trị này được hầu hết các cơ quan nhà nước sử dụng bởi tính bảo mật, tốc độ xử lý mạnh và thuận lợi cho phát triển hệ thống. Với đặc điểm ứng dụng được lập trình trên nền tảng .NET thì việc kết nối, truy xuất và hiển thị thông tin thuộc tính hoàn toàn bằng Tiếng Việt trên bảng mã Unicodephù hợp trong SQL Server mà không cần cài đặt thêm thư viện kết nối.

Mô hình Webserver bao gồm ứng dụng webGIS chạy trên nền tảng dịch vụ IIS thông qua giao thức tiêu chuẩn HTTP, FPT... kết hợp với các WebServices dưới dạng Rest API dành cho bản đồ số đảm bảo việc cập nhật, cung cấp, trình bày thông tin đầy đủ, chính xác. Sử dụng giải pháp phần mềm của hãng ESRI (ArcGIS Server và ArcDesktop, ArcEngine) làm nền tảng phát triển [4].

Các định dạng chuẩn trao đổi, tích hợp thông tin: theo cấu trúc các định dạng chuẩn dữ liệu OpenGIS, phục vụ cho việc mở rộng và liên kết với các hệ thống GIS khác, bao gồm: WMS (Web Map Service), WFS (Web Feature Service). Font chữ: tiếng Việt theo chuẩn Unicode 6909: 2001.

Thông qua ngôn ngữ lập trình $\mathrm{C} \#$ trong môi trường ASP.NET, đề tài đã tiến hành xây dựng hệ quản trị dữ liệu thuộc tính và tích hợp bản đồ chuyên đề về tài nguyên đất của thành phố Uông Bí.

WebGIS được xây dựng với phiên bản chạy Desktop. 


\subsection{Phưong pháp nghiên cúu}

Qua phân tích các yêu cầu sử dụng, chức năng cung cấp, xử lý và quản lý dữ liệu, đề tài đã thực hiện các phương pháp dưới đây để hình thành WebGIS $[1,4]$ :

- Thu thập dữ liệu, số liệu: các loại dữ liệu về nền địa lý, địa hình cơ sở, dữ liệu ảnh vệ tinh, bản đồ hiện trạng, bản đồ quy hoạch, địa chính, bản đồ thổ nhưỡng và tất cả các bản đồ chuyên đề về thoái hóa đất, về chất lượng đất và ô nhiễm đất đã được chuẩn hóa theo quy định về nội dung và cấu trúc dũ liệu tại Thông tư 75/2015/TTBTNMT và Thông tư 60/2015/TT-BTNMT.

- Phân tích yêu cầu sử dụng: xác định danh mục các đối tượng quản lý (ĐTQL) và thông tin chi tiết cho từng ĐTQL; xác định các quan hệ giữa các ĐTQL; các yếu tố ảnh hưởng đến WebGIS; vẽ sơ đồ quy trình, nghiệp vụ, mô hình hóa biểu đồ trường hợp sử dụng (THSD) nghiệp vụ.

- Thiết kế: thiết kế kiến trúc WebGIS, thiết kế biểu đồ THSD, biểu đồ hoạt động, biểu đồ tuần tự, biểu đồ lớp, thiết kế giao diện Web.

- Dữ liệu và CSDL được thiết kế và xây dựng từ kết quả nghiên cứu của đề tài mã số BĐKH10.16-20.

- Lập trình xây dựng WebGIS bằng $C^{\#}$ trên nền ASP.NET.

- Vận hành thử nghiệm WebGIS: hệ thống được cài đặt trên máy chủ (Server) và vận hành thử nghiệm với địa chỉ tên nguồn cài đặt vào máy chủ (server), tên miền truy cập: http://tainguyendat-quangninh.vn, cho phép cộng đồng, người dân và doanh nghiệp truy xuất vào hệ thống để xem thông tin, văn bản quy phạm pháp luật, bản đồ và đặc biệt là cung cấp thông tin về các vi phạm trong sử dụng đất, trong quản lý đất, trong bảo vệ tài nguyên đất.

\section{Kết quả}

\subsection{Xây dụng CSDL trục tuyến}

WebGIS hỗ trợ giám sát biến động tài nguyên đất có cơ sở dữ liệu được xây dựng bao gồm dữ liệu và cấu trúc dữ liệu theo đúng quy định tại Thông tư 75/2014/TT-BNTMT quy định về cơ sở dữ liệu đất đai, ngoài ra các dữ liệu về thuộc tính lý-hóa-sinh học đất, về thoái hóa đất, chất lượng đất, ô nhiễm đất được quản lý theo lớp dữ liệu không gian theo hướng dẫn của Thông tư 60/2015/TT-BTNMT và Thông tư 14/2012/TTBTNMT. Dũ liệu thuộc tính được lưu trữ dưới dạng các bảng trong CSDL, đồng thời gắn với dữ liệu không gian bằng các trường khóa.

Nguồn dữ liệu nền như; ảnh vệ tinh (có lựa chọn theo năm, theo huyện); DEM. (có lựa chọn theo huyện); bản đồ địa hình (có lựa chọn theo huyện); bản đồ thổ nhưỡng (có lựa chọn theo huyện); bản đồ lớp phủ đất (có lựa chọn theo năm, theo huyện); bản đồ hiện trạng sử dụng đất tỉnh Quảng Ninh (có lựa chọn theo năm); bản đồ hiện trạng sử dụng đất cấp huyện (có lựa chọn theo năm và theo huyện).

\subsection{Mô tả chức năng chi tiết của hệ thống WebGIS}

Chức năng website được thiết kế cho 2 nhóm đối tượng như sau:

Người dùng cuối: được phép thực hiện các dịch vụ:

-Xem các bản đồ về tài nguyên đất, tra cứu văn bản về đất đai trên giao diện Web.

-Cung cấp thông tin về vi phạm trong quả lý đất đai (người dùng chọn loại hình vi phạm, vẽ vị trí vi phạm, cung cấp thông tin về vi pham, cung cấp hình ảnh, video).

-Cung cấp thông tin về vi phạm trong sử dụng đất đai: (người dùng chọn loại hình vi phạm, vẽ vị trí vi phạm, cung cấp thông tin về vi pham, cung cấp hình ảnh, video)

-Cung cấp thông tin về bảo vệ tài nguyên đất: (người dùng chọn loại hình bảo vệ tài nguyên đất, vẽ vị trí xảy ra, cung cấp thông tin về hiện tương, cung cấp hình ảnh, video)

- Các thông tin thu nhận từ người dân cung cấp thông qua giao diện bảng và được lưu trong 
một file *.xls (Ngày tháng cung cấp, địa chỉ cung cấp, nội dung cung cấp, ghi chú); người dùng vẽ trực tiếp trên màn hình Desktop vị trí xảy ra vi phạm hoặc xảy ra hiện tượng, các thông tin này sẽ được lưu trên Server theo từng lớp riêng biệt và gắn với thông tin thuộc tính .

Người quản trị: Được cấp quyền truy cập vào trong trang quản trị hệ thống khi đã đăng nhập thành công.

- Đăng nhập:khi nhập đúng tên đăng nhập và mật khẩu thì được phép truy cập vào hệ thống và cập nhật mới CSDL cho website.

- Nhập dữ liệu, cập nhật các thông tin thuộc tính về các bản đồ mới, ảnh vệ tinh mới.

\subsection{Giao diện chính của WebGIS}

Trang Web có địa chỉ http://Tainguyendatquangninh.vn

Cấu trúc của Website gồm 6 menu chính gồm: Trang chủ. Giới thiệu; Tài nguyên đất; Giám sát sử dụng đất; Giám sát quản lý đất đai; Bảo vệ tài nguyên đất; Tài liệu văn bản. (Xem hinh 1)

\subsection{Chức năng của hệ thống WebGIS quản lý dũ liệu tài nguyên đất}

Menu giới thiệu: giới thiệu về tỉnh Quảng Ninh về vị trí địa lý, tình hình KT-XH. Giới thiệu về tài nguyên đất tỉnh Quảng Ninh.

Menu tài nguyên đất: cung cấp thông tin đến người dùng các bản đồ về Ảnh vệ tinh (có lựa chọn theo năm, theo huyện); DEM (có lựa chọn theo huyện); Bản đồ địa hình (có lựa chọn theo huyện); Bản đồ thổ nhưỡng (có lựa chọn theo huyện); Bản đồ lớp phủ đất (có lựa chọn theo năm, theo huyện); Bản đồ hiện trạng sử dụng đất tỉnh Quảng Ninh (có lựa chọn theo năm); Bản đồ hiện trạng sử dụng đất cấp huyện (có lựa chọn theo năm và theo huyện); Bản đồ hiện trạng sử dụng đất cấp xã/phường (có lựa chọn theo năm và theo xã); Bản đồ ô nhiễm môi trường đất (có lựa chọn theo năm, theo huyện); Bản đồ chất lượng đất (có lựa chọn theo năm, theo huyện); Bản đồ thoái hóa đất (có lựa chọn theo năm, theo huyện).

Menu giám sát sử dụng đất là công cụ để người dân và cộng đồng cung cấp thông tin về vi phạm pháp luật đất đai trong quá trình sử dụng đất của người sử dụng đất, theo Điều 20 Luật đất đai 2013 bao gồm các hành vi sau:

Không sử dụng đất, sử dụng đất không đúng mục đích.

Không thực hiện đúng quy định của pháp luật khi thực hiện quyền của người sử dụng đất.

Nhận chuyển quyền sử dụng đất nông nghiệp vượt hạn mức đối với hộ gia đình, cá nhân.

Sử dụng đất, thực hiện giao dịch về quyền sử dụng đất mà không đăng ký với cơ quan nhà nước có thẩm quyền.

Không thực hiện hoặc thực hiện không đầy đủ nghĩa vụ tài chính đối với Nhà nước.

Lấn, chiếm, hủy hoại đất đai.

Gây cản trở cho việc sử dụng đất của người khác.

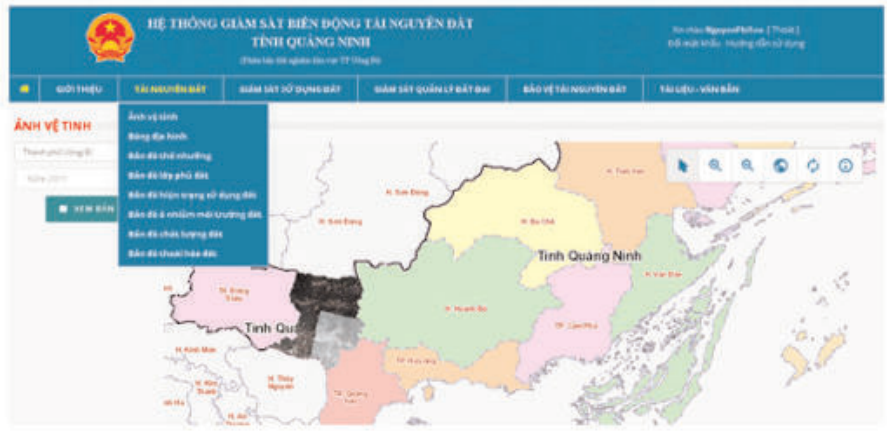

Hình 1: Giao diện trang chủ của WebGIS khu vục thử nghiệm TP Uông Bí 
Cản trở, gây khó khăn đối với việc thực hiện quyền của người sử dụng đất theo quy định của pháp luật.

Menu giám sát quản lý đất đai là công cụ để người dân và công đồng cung cấp các thông tin về:

- Mất/thay đổi mốc địa giới hành chính. đất.

- Vi phạm về quy hoạch, kế hoạch sử dụng

- Vi phạm quy định về giao đất, cho thuê đất, chuyển đổi mục đích sử dụng đất.

- Viphạm về thu hồi đất, bồi thường, hỗ trợ, tái định cư.

- Vi phạm về trưng dụng đất.

-Vi phạm về quản lý đất được nhà nước giao để quản lý.

- Viphạm về thực hiện trình tự, thủ tục hành chính trong quản lý và sử dụng đất.

Menu bảo vệ tài nguyên đất là công cụ để người dân và công đồng cung cấp các thông tin về:

Khu vực sạt lở đất, sạt lở bờ sông biển;

Khu vực khai thác đất, khai thác khoáng sản trái phép;

Khu vực nguồn gây ô nhiếm đất, nước.

Quy trình thao tác của người dùng cuối khi cung cấp thông tin cho cơ quan quản lý như sau: nếu người dân phát hiện các vi phạm có liên quan đến quy hoạch sử dụng đất sẽ lựa chọn chức năng: "Giám sát sử dụng đất theo quy hoạch". (Xem hình 2)

Chọn đơn vị hành chính cấp huyện cần giám sát: bao gồm chọn đơn vị huyện/thị, sau đó chọn đơn vị xã/phường, Web sẽ tự động phóng đến đơn vị xã/phường để người dùng thao tác tiếp.

Để người dùng có thêm thông tin về quy hoạch, hiện trạng sử dụng đất hoặc nền ảnh vệ tinh, lúc này có thể mở các bản đồ quy hoạch, sử dụng đất, bản đồ địa chính và ảnh để tham chiếu. Trong WebGIS sẽ có chức năng mở đồng thời 4 nguồn dữ liệu trên một giao diện để hỗ trợ cho việc khoanh vẽ vị trí vi phạm. Với 4 nguồn tài liệu này cũng là căn cứ để xác định hình thức vi phạm bên cạnh sự hiểu biết của người dân và cộng đồng về đất đai tại địa phương. (Xem hình 3)

Sau khi xem xét bản đồ quy hoạch và thực tế sử dụng đất tại địa phương, người dân đã phát hiện trường hợp sử dụng đất sai quy hoạch và tiến hành cung cấp thông tin. Sử dụng công cụ để khoanh vẽ phạm vi sai phạm, lưu ý có thể Zoom ảnh phóng đại đến mức cao nhất để nhận diện vị trí. (Xem hình 4)

Thông tin về vi phạm sử dụng đất do người dân và cộng đồng cung cấp người quản trị tiếp nhận sau đó chuyển cho cán bộ chuyên môn kiểm chứng để đảm bảo tính đúng đắn của thông tin. Trước hết người cán bộ kỹ thuật so sánh bản đồ hiện trạng sử dụng đất, bản đồ quy hoạch, bản đồ kế hoạch sử dụng đất thời điểm giám sát, ảnh vệ tinh với thông tin nhận được từ người dân để



Hình 2: Lựa chọn chức năng cung cấp thông tin theo loại hình vi phạm 
xác định sơ bộ các biến động đúng pháp luật. Cán bộ địa chính cấp xã/phường được giao nhiệm vụ kiểm chứng và báo cáo tình hình về tính chính xác của thông tin đã được người dân và cộng đồng cung cấp thông qua WebGIS. Trong quá trình kiểm chứng thực địa cần thu thập đầy đủ các tư liệu, tài liệu, văn pháp pháp lý về hồ sơ khu vực có thông tin sử dụng sai mục đích, các hoạt động quản lý không đúng pháp luật. Cán bộ địa chính cấp xã/phương có trách nhiệm kiểm tra vị trí, phạm vi, loại hình vi phạm/tác động, đối tượng vi phạm, tính chất của tài nguyên đất bị vi phạm/tác động, mức độ và thời gian vi phạm/tác động. Các thông tin này được thông báo cho quản trị hệ thống bằng văn bản.

Với chức năng công khai thông tin đất đai, WebGIS sẽ đảm bảo cho cơ quan quản lý tài nguyên và môi trường ở địa phương nâng cao năng lực quản trị hành chính công, góp phần thực hiện được 1 trên 6 chỉ số nội dung của PAPI cấp tỉnh [5].

Như vậy WebGIS sẽ có hai nội dung về vi phạm đất đai trong công tác quản lý và sử dụng đất trên giao diện https://TainguyedatQuangNinh.vn, thông qua đó người dân và cộng đồng sẽ biết thêm về các nội dung vi phạm. Cơ quan quản lý sẽ nhận được các thông tin ban đầu về vi phạm ở đâu, tính chất vi phạm và đối tượng vi phạm. Đây là vấn đề cần thiết thúc đẩy sự minh bạch trong quản lý đất đai, đảm bảo sự tham gia của người dân và cộng đồng trong sử dụng đất đai theo pháp luật.

Hiện WebGIS đang trong quá trình thử

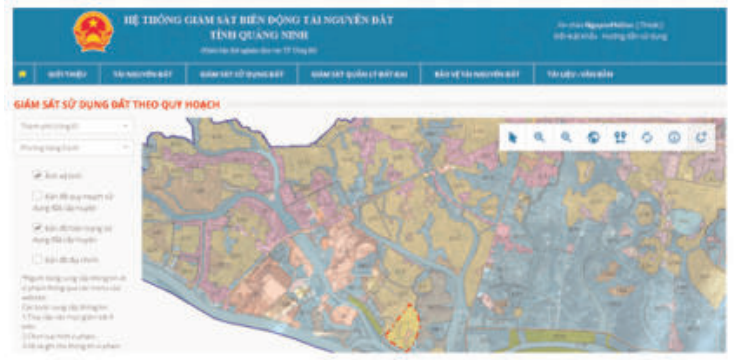

Hình 3: Mở đồng thời ảnh vệ tinh và bản đồ hiện trạng nghiệm, số lượng truy cập nhiều, một số thông tin cung cấp đã và đang được xác thực độ tin cập tính chính xác của thông tin, sau đó được tổng hợp trình cơ quan có thẩm quyền giải quyết.

\section{Kết luận}

WebGIS được xây dựng nhằm mục đích tạo một kênh thông tin để tiếp nhận các phản ánh từ cá nhân, tổ chức cung cấpvề các vi phạm trong sử dụng đất, quản lý đất, giám sát bảo vệ tài nguyên đất. WebGIS được xây dựng với công nghệ tiên tiến hiện nay, có khả năng mở rộng hay nâng cấp các tiện ích, giao diện thuận lợi cho người sử dụng, các Usercase phù hợp với yêu cầu trong hoạt động giám sát tài nguyên đất. Ngoài ra, WebGIS còn cung cấp cho cộng đồng và xã hội các thông tin về tài nguyên đất, phổ biến văn bản pháp luật trong lĩnh vực đất đai.

Ứng dụng WebGIS trong giám sát đất đai là rất tiện lợi, giúp tiết kiệm thời gian và công sức bởi “tai mắt" của dân có ở khắp mọi nơi, mọi lúc để cung cấp các thông tin vi phạm, góp phần bảo vệ tài tản quốc gia. Vấn đề là cơ quan quản lý và chính quyền phải động viên kịp thời, hỗ trợ tối đa và xử lý các thông tin nhanh chóng để tạo lòng tin. WebGIS được xây dựng bước đầu thử nghiệm áp dụng trên địa bàn thành phố Uông Bí tỉnh Quảng Ninh và sẽ được triển khai trên diện rộng sau khi đánh giá, rút kinh nghiệm. $\bigcirc$

\section{Tài liệu tham khảo}

[1]. Trần Hùng, 2011. Úng dụng GIS trong quản lý hạ tầng kỹ thuật đô thị tại Việt Nam. Kỷ yếu hội thảo ứng dụng GIS toàn quốc 2011. Tr 175-182.

(Xem tiếp trang 21)

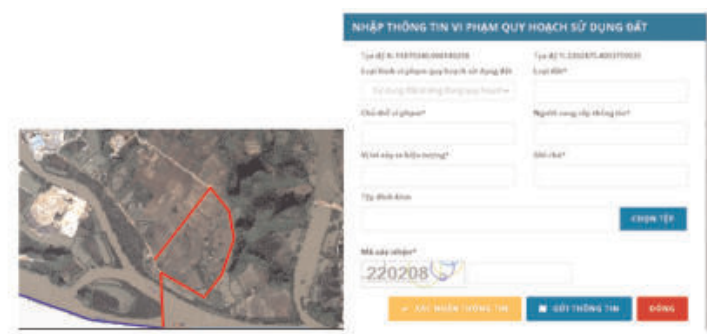

Hình 4: Khoanh vẽ vị trí vi phạm và nhập thông tin liên quan 